\title{
The Library Solution
}

\section{How Academic Libraries Could End the APC Scourge}

\author{
Jeff Pooley, Muhlenberg College \\ pooley@muhlenberg.edu
}

September 4, 2019

This preprint is a longer version of Jeff Pooley, "The Library Solution: How Academic Libraries Could End the APC Scourge," Items, September 3, 2019, https://items.ssrc.org/parameters/the-library-solutionhow-academic-libraries-could-end-the-apc-scourge/ 


\title{
The Library Solution: How Academic Libraries Could End the APC Scourge
}

\author{
Jeff Pooley, Muhlenberg College
}

The article processing charge (APC) is the specter haunting the open access movement. Advocates for OA face plenty of other obstacles, including tolled journal prestige, researcher inertia, and the lifedraining embrace of the publishing oligopolists. But the APC - the fee that many publishers charge authors to publish - is a homegrown problem. Most scholars cannot afford the fees, a fact masked by the privileged segment who can: scientists in the rich industrialized world, and scholars at a handful of elite Western universities. The rest of us-researchers from the Global South and non-scientists everywhere-are left with a bill we can't pay. So the prevailing APC regime fixes one barrier to access, for readers, by erecting another, for authors. That's a cruel irony.

We have a viable alternative, and it's gaining traction: The library subsidy. The idea is to divert the billions of dollars libraries pay to prop up the existing subscription ecosystem to fund its open access replacement. In this model, the library pays - not the reader and not the author. There's a poetic fitness to the idea: The same librarians affected by the steep pricing of Elsevier and Springer have the opportunity to underwrite a fair and open alternative. Academic librarians are among the most committed and active in the campaign to makeover scholarly publishing; they're even setting up inhouse publishing operations and joining forces with the university press system. Guided by their patronserving mission, libraries could replace the APC and, in a real sense, redeem the promise of open access.

One obvious rejoinder takes the form of a question: Isn't a library subsidy scheme just adding budgetdraining insult to serials-crisis injury? It's a fair point, since library budgets are already strained, and many are still recovering from sharp cuts in the wake of the Great Recession. The fact is, however, that the current, admittedly unjust system is funded through libraries - to the tune, by some estimates, of $\$ 10$ billion a year for STEM journals alone. This is, unavoidably, the pot of money that any OA alternative will need to draw from. If "why libraries?" is the question, the answer is that they're already paying. The financial carrot for the library ecosystem is that a subsidized OA future-even if commercial publishers remain in the mix -is likely to be cheaper than the current subscription regime.

Another objection inevitably creeps in, or at least a fear: What about free riders? Libraries that pay into the system get nothing in return-or at least nothing that their non-paying counterparts don't also obtain. The funds, after all, support open access for everyone-that's the whole point. What incentive 
does a librarian have to whittle down its budget for open works that - with others' contributions - will be available anyway? It's a fair question, though experiments with library subsidies, so far at least, have an answer: Libraries seem willing to pay. One reason is that librarians just aren't utility maximizers in the narrow sense assumed by the free-rider model. The logic of collective action-to invert Mancur Olsen's phrase-is stitched into the profession's ethic of shared responsibility. There is, too, the crucial point that publishers like the Open Library of Humanities (OLH) do offer participating libraries something in return: a stake in the platform's governance.

A thousand smaller objections, lots of them logistical, come to mind. How will subsidies get awarded? Will a competitive "grant" system threaten publishers' year-over-year operational stability? How will libraries juggle the two systems - the old and the new-over a long transition? What about government and foundation funders: Shouldn't they foot some of the bill?

Those are good questions, but we are, as we pose them, haggling over the details. The case for library subsidies stands on its own first-order merits. The APC model, with its tolled access to authorship, is the subscription model seen through a camera obscura: author paywalls in place of reading paywalls. Digital

publishing has real costs, but these shouldn't fall to authors or readers. The current, padlocked system is funded by libraries - which is to say tuition, state contributions, and endowment draws. So we already have a collective funding mechanism, premised on campus-wide access to scholarship. The replacement system promises more access and-with the Elsevier fat cut out-reduced cost.

The momentum, unfortunately, is with the APC model. Plan S, the European initiative to flip scholarly communication to OA, endorses author charges. Proposed restrictions, including a cap on APCs, were notably relaxed in the plan's revised guidelines released this summer. If implemented, and emulated, the current Plan S would lock in an OA regime that's already broken. So there's not much time to fight for a fair alternative.

\section{The Problem with APCs}

The author processing charge (APC) emerged in tandem with the open access movement itself. Publishing costs, in the internet era, were poised to fall, but no one disputed that expenses would remain. So the bill had to be paid somehow. The Budapest Open Access declaration, the 2002 manifesto that announced the OA movement, was nonchalant about the challenge. The document's authors cited "many alternative sources" that could cover the publishing costs, including government and foundation funders, universities themselves, and "friends of the cause of open access." The Budapest declarees' list ended with a fateful Boolean: "or even contributions from the researchers themselves." The APC option was there from the beginning. 
The OA movement's original schism was between "green" self-archiving (of an author's unformatted version) and "gold" publication (of a publisher's final PDF). The green option was nearly always free for authors, while the gold route-with its typeset polish - was sometimes free too. But the earliest OA publishers, like the for-profit BioMed Central, opted for an author fee. Just a month before the Budapest gathering, BioMed announced a "processing charge" for each article the group published-apparently coining the APC phrase in the process. $\$ 500$ was the initial charge, to be waived for authors in "developing countries" and in cases of "genuine hardship." The high-profile nonprofit Public Library of Science (PLOS) embraced the APC model on its 2003 launch. "Why should I have to pay to publish my paper?" asked an early FAQ on the PLOS website. "It costs money to produce a peer-reviewed, edited, and formatted article that is ready for online publication," PLOS answered, "and to host it on a server that is accessible around the clock." How much money? \$1500 an article, triple the BioMed price. PLOS justified the fee, tellingly, as a tiny fraction of the typical laboratory budget.

By 2004 BioMed's flagship Journal of Biology had matched PLOS's \$1500. And the established commercial publishers recognized a new revenue source. The same year Springer, the German publishing colossus, announced its "Open Choice" program: Authors could opt to pry their articles open in otherwise-closed journals ... for $\$ 3,000$. The round sum was, apparently, the maximum that funders like the Wellcome Trust would stomach. Springer's peers soon followed suit with "hybrid" and full-OA options of their own; they had, as an industry, turned open access lemons into lemonade.

So by mid-decade the mold was set. BioMed and PLOS had shown that science funders were willing to stitch APCs into their grants. Springer and Elsevier then joined the party-and doubled the cover charge. The "article processing" fee was, by then, a pretty lie. The charges were plainly untethered from actual publishing expenses, and few publishers - then or since-have been willing to open their books. (There's a lively debate over which factors set the price, but no one believes that actual article costs matter.) For the natural sciences, "open access" had come to mean $\$ 1500$ to $\$ 3000$ APCs - a cost that funders generally absorbed. And the model has worked, more or less, for the grant-supported sciences, at least in the rich West.

Today, APCs range from $\$ 500$ to over $\$ 5000$, with the commercial publishers' "hybrid" options the most expensive. The charges are climbing at three times the rate of inflation, in part because of the journaltitle prestige lock-in that also fuels subscription pricing. The scholarly publishing industry, among the world's most profitable, has continued to consolidate in the years since the hybrid model appeared. Springer is now the Springer Nature Group, and its fees $-\$ 5200$ for Nature Communications - are among the steepest. BioMed Central, the scrappy startup that pioneered the APC, was itself acquired by Springer in 2008.

The hybrid option is premised on double-dipping: The big publicly traded publishers feed at the subscription trough while noshing on OA subventions. The practice is so egregious that a number of 
large subscription consortia have held out for so-called "read and publish" deals. The idea is to bring subscriptions and APCs under the same contract, to prevent double-dipping. The enormous University of California library system canceled its Elsevier contract over the issue, prompting the Anglo-Dutch profiteer to buckle to Norway's read-and-publish demand. The deals are emotionally satisfying-as public, contract-ratified refusals of rapacity. But they are, at best, velvet bandaids to the APC problem: The contracts lock in the tolled oligopoly and, in a sense, legitimize the hybrid model. And the read-andpublish strategy leaves the APC in place for everyone else. The library consortia that negotiate the deals are, notably, from the wealthy West. So the patterned APC barriers to authorship are, if anything, exacerbated.

Unfairness - the patterned exclusion to authorship -is the core of the APC problem. It's true that only about a quarter of all journals indexed in the Directory of Open Access Journals (DOAJ) demand author charges (with APC-funded articles over half the OA total). The rest of the open journals are-in keeping with the polychromatic nomenclature- "platinum": They're free to read, and yet charge no author fees. ("Diamond" is another common label for a no-APC title.) If close to three-quarters of the world's OA journals are already APC-free, why fret over a small band of irredentists?

One reason is that most of the platinum journals are more like cubic zirconia: They run on creaky OJS installations and editorial pluck. Many publish irregularly, and with uneven quality. The journals limp along, with estimable doggedness, but are often one devoted editor away from the digital graveyard. Vital publication functions, like copy editing, preservation, DOI minting, and indexing, may get sacrificed on the altar of resource-constrained expediency. These underfunded titles-which tend to cluster in the social sciences and pockets of the humanities - are already up against a punishing prestige economy. The American Sociological Review, published by SAGE, has an 80-year head start on the Open Journal for Sociological Studies-and all the self-amplifying appeal that accrues to a society-sponsored flagship. If the $A S R$ is your competition, you need-at the very least-good copy editing.

So lots of OA journals are APC-free, but that doesn't mean that they're sustainable endeavors. As the Budapest signatories realized, reliable funding is a necessary baseline for open access publishing-even when the software is free and much of the labor donated. It's true that funded platinum journals exist, with actual year-over-year budgets, if not in great numbers. There is, in Latin America and elsewhere in the Global South, a tradition of modest national and university subsidies for non-profit, scholar-led journals - though that system is itself under threat. Other funded, no-APC journals, like the Beilstein Journal of Organic Chemistry, are supported by nonprofit foundations. Still others are underwritten by scholarly associations, like the Society for Cultural Anthropology's Cultural Anthropology. But most learned societies are in no position to subsidize platinum journals. They are, by and large, in the reverse position: woefully dependent on publishing revenues to prop up their other operations. Even the platinum success stories, like Cultural Anthropology, lead a hand-to-mouth existence. 
For all the challenges of the platinum route, there is growing and spirited opposition to the APC model. Some critics point to the APC as the key enabler of predatory publishing - of the "Dear esteemed author" type-since the legitimate industry demands fees too. One upshot is that non-predatory journals are tarred, by association, with the pay-to-play brush in many scholars' minds. There is, too, the perverse incentive baked into the APC's per-unit funding logic. Publishers' revenue is hitched to their volume of posted articles, a dynamic that may very well worsen academia's over-publication problem. More fundamentally, the per-article mode is mismatched to the actual costs of publishing; fixed overhead-including funds to sustain shared infrastructure-is left scrounging for the APC leftovers.

So there are lots of practical problems with the APC model. But its key defect is moral: APCs close off authorship to most of the world's scholars. And that author wall is erected, crucially, along existing lines of disciplinary and North-South inequalities. The model's bankruptcy is widely recognized outside Europe and North America. In the Global South, regional consortia and national scientific bodies have a of anti-APC . A group of Latin America and Caribbean nations, for example, recently declared an APCfunded OA system "impossible" for participating countries. The UNESCO-supported AmeliCA coalition (“Open Knowledge for Latin America and the Global South"), established late last year, came out strongly against APCs. In a recent interview, Arianna Becerril-García-a Mexican computer scientist and the group's director-referred to the author-fee model as "ravenous, exclusionary and unsustainable." The world's scholarly communication system is already warped Northward, a problem that the APC may well exacerbate. A recent large-scale analysis of Springer and Elsevier's OA articles was inconclusivefor the most part, the gross inequalities in the existing tolled system are merely echoed in the OA output. The study's authors note, however, that scholars from the Global South typically publish in lower-ranked journals, presumably because the APCs are lower. They cite evidence, too, that academics from the South are far more likely to pay APCs out of pocket-and rarely receive waivers, despite policies touted by publishers. Even Alison Mudditt, CEO of the APC-dependent PLOS, warns that an APC-centric model risks "[h]ardwiring the exclusion of research produced in the Global South."

Social scientists and humanities scholars (SSH) are the other big, overlapping class of excluded authors. Most SSH academics - at least those outside a handful of rich institutions or national systems that offer an APC pool-have no realistic access to grants or other external funds to cover the fees. Hence the , registered along disciplinary lines, on attitudes toward author charges-and, perhaps as a result, toward $O A$ itself. A recent survey found that humanists and social scientists were far more downcast about gold OA than their natural science counterparts, largely due to fears that they won't be able to publish in an APC world. This core reality - that most non-scientists simply can't afford author fees-helps to explain the small percentage (13 percent) of OA journals in these fields that charge fees. At the article level, the gap is gigantic: more than two-thirds of biomedical and STEM articles are APC-supported, compared to a fifth (22 percent) in the other disciplines.

If the future of open access is pay-to-play, most of us won't be publishing. 


\section{The Library Solution}

The spectral character of the APC - its fundamental incompatibility with a just OA system-suggests an alternative model, centered on the library. Since readers and authors alike can't be charged, we need a collective payer - a third party to cover the costs of scholarly communication. In the early years of the open access movement, as the APC model took hold in the sciences, a handful of OA proponents identified the library as a viable substitute. Back in 2005, Bo-Christer Björk proposed what he called "institutional open choice" - which meant, basically, redirecting existing subscription budgets to OA funding consortia. John Willinsky, in his important 2006 book The Access Principle, floated a similar idea, "publishing cooperatives" made up of libraries and society publishers. Willinsky envisioned an infrastructural role for libraries, in addition to fees based on existing subscription outlays. Many of these early schemes explicitly called out the humanities and social sciences, on the assumption - a prescient one-that the APC model wouldn't work for these fields.

It took a few years, but by the early 2010s a handful of library-funded OA initiatives were successfully launched. An early foray in library subsidies was Knowledge Unlatched (KU), a nonprofit established in 2012 by publishing veteran Frances Pinter. Her idea was to form a group of libraries - a "Global Library Consortium," in Pinter's phrase-to pool resources to pay publishers to openly license their books. Knowledge Unlatched, in its initial 2013 round, unlocked 28 books from 13 publishers with the backing of nearly 300 libraries. The tally of books, publishers, and libraries swelled over subsequent rounds. Pinter's experiment showed that libraries could be tapped to pry open access for their patrons-though $\mathrm{KU}$ has since been acquired by a for-profit consulting firm in a murky and controversial deal.

arXiv, the now-venerable preprint server for physics, math, and computer science, was another early adopter of the library subsidy model. In 2010 the group, rattled by the Great Recession, decided to reduce its dependence on its host, Cornell. arXiv rolled out a membership model in 2013, asking universities to contribute based on their faculties' download counts. Member institutions get some input on arXiv's future, as well as better statistics - and over 200 universities have signed up.

It turns out that 2013 was a big year for the new consortia model. A pair of UK humanities scholars founded the Open Library of Humanities (OLH), with seed money from Mellon. From the beginning the OLH was centered on a "library partner subsidy" scheme-on the assumption that humanities scholars will never be able to afford the steep author fees already common for OA publication in the natural sciences. Why not tap the funds propping up the tolled system instead-with the organized cooperation of Elsevier-oppressed librarians themselves? The group's operations are supported by over 200 library partners who contribute an annual fee, based on university's size and location, ranging from $\$ 600$ to $\$ 3000$. Participating libraries gain a seat on the OLH Library Board, with the power to approve new 
journals and other budget increases. The group's 27 journals published almost 500 open articles last year at a cost, crucially, that worked out to less than $\$ 3$ per institution per article.

A third proof-of-concept launched the same year: the particle physics OA journal consortium $\underline{\text { SCOAP3}^{3}}$. Spearheaded by Geneva-based CERN, the partnership-formally called the Sponsoring Consortium for Open Access Publishing in Particle Physics-has over three thousand institutional members, most of them libraries. The partners redirect the dollars they once spent subscribing to the dozen or so journals -representing most of the field's published output-to SCOAP ${ }^{3}$. The consortium then distributes the cash to the now-open journals, funding over 28,000 articles since its founding.

Many of the library-subsidy schemes envision a role for libraries beyond their budgets. So it was fitting that-also in 2013-over 50 leading academic libraries established a Library Publishing Coalition devoted to sharing knowledge around "publishing and distributing academic and scholarly works". Inhouse library publishing units have grown steadily in the half-decade since, in some cases merging with their university press counterparts.

Over these same years, a number of other successful library-funded publishing initiatives have cropped up. In 2016 over 50 U.S. liberal arts college libraries pooled funds to establish Lever Press. The partner libraries help govern the press, which recently published its first book on Michigan's new multimedia Fulcrum platform. At Lever there are no author subventions (i.e., BPCs) by design, with the production costs covered instead by the participating libraries. Even established library-funded consortia with tolled products are using the funding model to experiment with open publishing. ATLA, née the American Theological Library Association, recently started its own Open Press with a small-scale monograph program.

The library consortial model adopted by OLH, Lever, SCOAP3, and the others doesn't rule out involvement from other third-party funders. Indeed, SCOAP 3 and arXiv count private foundations, research institutes, and national science agencies as members. And for good reason: One way or another these institutions - which, after all, front many of the APCs currently sloshing around in the system - should help underwrite any collective OA funding scheme to emerge. A comprehensive, Mellon-funded 2016 study, centered on North American research institutions, predicted that funders would need to cover some of the costs - that library budgets, alone, wouldn't be enough to prop up a fully OA system. That's debatable-the study focused on the sciences and assumed an APC regime (largely underwritten by institutions) rather than the subsidy model proposed here. But the study's core point is compelling: Funders should have skin in the game.

Likewise, some have argued - notably Rebecca Kennison and Lisa Norberg in a 2014 white paper-that universities, rather than libraries, should bear the main budgetary burden. And it's true that many of the big national and regional publishing cooperatives-France's OpenEdition, Erudit in Francophone 
Canada, Redalyc and SciElo in Latin America-are funded, in part, with direct university subsidies. So there's nothing sacred about libraries per se; collective funding for an OA future can and should draw on foundations, agencies, and universities too. The major source of funds, however, is likely to come from current subscription expenditures - and hence from libraries.

It is telling that a number of recent schemes-mostly focused on journals published by learned societies -are predicated on subscription revenue. These "subscribe-to-open" initiatives (like Libraria (disclosure: I am involved with the project) and a new effort by OLH) start from the premise that scholarly associations won't easily give up their serials proceeds since, in many cases, these dollars subsidize their other activities. The basic subscribe-to-open idea is to ask societies (and their publishing partners, if any) to accept library payments more-or-less equivalent to the subscription price they already receive. The journals, in these schemes, then flip to open, but without draining societies' coffers. There are plenty of details to work out, but the Libraria and OLH projects (together with SCOAP3's successful example along these lines) suggest a broader settlement, a framework that could be applied across the board.

This is the library solution: a collectively funded publishing ecosystem, APC-free and centered on the academic library. Its core principle is that budgets used to acquire or subscribe to tolled materials be repurposed to underwrite an open access alternative. The money is in the system, the APC model is morally bankrupt and unworkable, and OA itself is inevitable. If pay-to-read is off the table, and pay-topublish too, then it's left to the university system to pick up the bill. And our institutions are already paying, through libraries, for the closed system that OA is poised to displace. As Ralf Schimmer, Kai Karin Geschuhn, and Andreas Vogler argued in a compelling 2015 paper, the large-scale shift to open access requires an "equally large-scale transformation or liberation of the library acquisition budgets." The point, in other words, is to strike a grand bargain among libraries, societies, publishers, and other funders, with the aim to repurpose the funds in the existing tolled regime.

Making the case for the library solution-spelling out its basic appeal-is of course the easy part. There are, needless to say, lots of coordination problems and divergent interests to contend with. A thorough 2017 report supported by the Commission makes for a sobering read: The authors identified six major roadblocks, including "no clear route to transition for subscription publishers." Even assuming agreement in principle on a library-centric approach, the implementation questions ask themselves. How will the monograph, and the university press system, be brought into the OA fold? How will a subsidy scheme that works with existing publishers, some of them aggressively for-profit, carve out funds to pay for the existing universe of $O A$ titles and publishers? What role for in-house library publishing and formal partnerships? How can support for an open and nonprofit infrastructure be secured and guaranteed? How can non-library funders like foundations contribute their share to a collective funding mechanism? How would such a subsidy scheme even work? Would there be funding consortia that operate along disciplinary lines, for example? If so, how would they be governed? And how would disciplinary, NorthSouth, and language inequalities be addressed? 
Those are all knotty questions, of course. They promise painful negotiations and tough decisions around values and priorities among a motley array of constituencies. But those conversations are unavoidable anyway. And if we rule out APCs from the start, we will, at least, avoid a constitutive blunder.

\section{The Perils of Plan S}

The open access movement has lingered, for some years now, at a decisive crossroads. Thanks to Plan $\underline{\mathrm{S}}$, there's almost no time left to dally. The Europeans, in the first draft guidelines, were ambivalent on the APC question: The plan anointed the author charge as a viable publishing model, but also announced caps and a ban on the hybrid option. The revised guidelines, released in early June, were a step backward: APC caps were dropped in favor of "transparency," despite evidence that the fees are resistant to market discipline. And commercial publishers were granted much more flexibility in phasing out the predatory hybrid model.

The news was disappointing, if not surprising: Europe, especially in the North, has embraced the APC model with special gusto. Even the otherwise praiseworthy Open Access 2020 Initiative, centered in Europe, is notably agnostic on the APC question. There is, on the continent, palpable enthusiasm for "transformative agreements" of the read-and-publish variety, as well as a loose consensus that there's enough money in the legacy system to pay for OA. But there remains, with Plan S partners and other key constituencies, a blind spot around the patterned injustice of the APC. As the indefatigable OA journalist Richard Poynder noted earlier in the year, "If pay-to-publish is baked into the new OA environment, researchers in the South will be priced out of the 'common intellectual conversation and knowledge' that the [Budapest Declaration] promised."

So the Plan S momentum in Europe is a mixed blessing at best-a welcome accelerant, for sure, but one that risks locking in the author charge. The plan's constituent members appear confident that market competition will bring APC prices down. They are probably wrong about that, but at a fundamental level the amount doesn't matter. The Plan S faith in the pricing mechanism echoes the old dilemma of classical liberalism: Everyone is free, as the saying goes, to sleep under the bridges of Paris. There is no fee, however modest, that will be affordable to most of the world's scholars. 